\title{
IMPLEMENTASI SCL (STUDENT CENTERED LEARNING) PADA PEMBELAJARAN KULIAH JARINGAN KOMPUTER (STUDI KASUS: POLITEKNIK TELKOM)
}

\author{
Yahdi Siradj \\ Politeknik Telkom, Jln. Telekomunikasi Terusan Buah Batu Bandung \\ e-mail: yahdi@politekniktelkom.ac.id
}

\begin{abstract}
Nowadays the process of teaching and learning not must wear conventional style where lecturer explained the matter in front of class, and student listened. By Technology Development learning was introduced many new methods which can optimalized the absorb knowledge inside or outside class, at once interactive and pleasure. Such as Student Centered Learning (SCL). On lecture matter Computer Networks in the Politeknik Telkom, SCL method can be implemented with combination of e-quiz, cloud based sharing files, toke Games, and dividing teaching session in the class become Ihour discussion and One hour consultation with lecturer. This method combinantion make Computer Networks learning more effective, interactive, and pleasure.
\end{abstract}

Keywords: Student Centered Learning, Computer Networks, E-quiz, Cloud, Game

\begin{abstract}
ABSTRAK: Saat ini proses pengajaran dan pembelajaran tidak harus bergaya konvensional dimana dosen menerangkan di depan kelas, dan mahasiswa mendengarkan di mejanya masingmasing. Melalui perkembangan teknologi pendidikan diperkenalkan berbagai metode baru yang dapat mengoptimalkan tingkat penyerapan ilmu di kelas maupun di luar kelas, sekaligus interaktif dan menyenangkan. Salah satunya adalah Pembelajaran berpusat pada siswa (SCL). Pada mata kuliah Jaringan Komputer di Politeknik Telkom, metode SCL diimplementasikan dengan memadukan e-quiz, cloud based sharing files, token game dan membagi sesi pengajaran di kelas menjadi 1 jam diskusi dan 1 jam pembahasan oleh dosen. Perpaduan metode ini menjadikan pembelajaran Jaringan Komputer menjadi lebih efektif, interaktif, dan menyenangkan.
\end{abstract}

Kata kunci: Pembelajaran berpusat pada siswa, Jaringan Komputer, E-quiz, Cloud, Game

\section{PENDAHULUAN}

Model pengajaran di perguruan tinggi cenderung menggunakan pola ceramah (lecturing) dimana dalam satu sesi kelas Dosen menjelaskan materi kuliah secara terus menerus. Posisi mahasiswa hanya sebagai pendengar yang sesekali bertanya di tengahtengah perkuliahan. Metode ini bersifat satu arah dan terasa menjemukan, karena dosen cenderung mendominasi dan mahasiswa cenderung pasif. Tingkat pencapaian mahasiswa biasanya sebagian besar bergantung dari seberapa baik dosen dalam menyampaikan materi pembelajaran. Teknologi yang digunakan dalam mengajar biasanya berupa slide presentasi yang sudah dipersiapkan sebelumnya dan ditampilkan menggunakan proyektor. Metode ini disebut de-ngan Teacher Centered Content Learning (TCCL).

Sistem ini juga yang terjadi pada proses pembelajaran kuliah Jaringan Komputer pada awal 2011 di Politeknik Telkom. Padahal, Jaringan Komputer bukanlah mata kuliah teori yang cukup difahami teori-teorinya tetapi juga harus diimplementasikan meski dalam tataran praktikum di lab sampai mahasiswa terampil menguasai kompetensi tertentu.

Kondisi pengajaran mata kuliah Jaringan Komputer sebelum implementasi SCL adalah pertemuan dilaksanakan 
sebanyak dua kali seminggu dengan total 16 minggu. Pertemuan pertama diisi oleh dosen dengan teori-teori pendukung yang terbagi atas 10 Bab. Pertemuan kedua diisi dengan praktikum (dibantu asistem praktikum) yang dilaksanakan di laboratorium jaringan. Bentuk penilaian dilakukan dengan ujian tulis di tengah semester yang disebut UTS dan di akhir semester yang disebut UAS. Nilai akhir didapat dengan menggabungkan $40 \%$ nilai UTS ditambah $60 \%$ nilai UAS

Sistem ini memiliki banyak kekurangan jika dilihat dari pencapaian tujuan. Pertama, untuk tataran lembaga pendidikan vokasional pemahaman teori bukanlah tolak ukur dari parameter wisudawan yang ingin dihasilkan. Sesuai dengan Undang Undang No. 20 tahun 2003 pasal 15 dijelaskan bahwa pendidikan vokasi merupakan pendidikan tinggi yang mempersiapkan peserta didik untuk memiliki pekerjaan dengan keahlian terapan tertentu maksimal setara dengan program sarjana. Penilaian secara ujian tertulis tidak memperlihatkan kompetensi praktek/keahlia terapan yang seharusnya dicapai mahasiswa. Kedua, beban pengajaran terlalu dititikberatkan ke pihak dosen dengan menyampaikan materi secara detail, melaksanakan ujian tertulis dan memeriksanya secara manual kemudian mengumumkan nilai kepada mahasiswa. Padahal, jika merujuk ke kurikulum KBK, mahasiswa harus ditrigger agar terbiasa belajar mandiri, mencari informasi seluas-luasnya dan ditantang dengan permsalahan untuk menumbuhkan kebiasan ingintahunya. Artinya, sistem pendidikan vokasional harus menitikberatkan pada kemauan mahasiswa mencari solusi, mempraktekkan dan implementasi solusi tertentu. Ketiga, mahasiswa tidak terbiasa dengan insting troubleshooting karena terlalu dicekoki dengan teori. Akibatnya mahasiswa tidak terampil jika menghadapi masalah baru di lapangan. Yang ada adalah mahasiswa mudah menyerah dan tidak gigih mencari solusi.

Paper ini mencoba mengimplementasikan dan mengevaluasi metode baru yang membalik kondisi tersebut sehingga keaktifan mahasiswalah yang berperan dalam tercapainya kesuksesan penyerapan ilmu lewat sering bertanya, diskusi, mengerjakan soal mandiri, praktik dan lainnya. Dosen sendiri perannya bergeser menjadi fasilitator dan motivator yang memberikan pengarahan agar mahasiswa senantiasa giat mencari informasi dan pengetahuan Di samping tetap memberikan materi kuliah. Untuk mencapai kondisi tersebut diperkenalkanlah metode Student Centered Learning(SCL) dan alat-alat pendukungnya agar lebih efektif mencapai tujuan yang diinginkan. Paper ini adalah hasil pengamatan penerapan SCL yang sudah diterapkan sejak pertengahan 2011 pada perkuliahan Jaringan Komputer di Politeknik Telkom.

\section{Student Centered Learning}

Politeknik Telkom sebagai institusi vokasional yang mengejar pencapaian kompetensi bagi mahasiswanya membutuhkan sistem pengajaran yang lebih menggali potensi mahasiswa dan mewujudkannya dalam bentuk kompetensi dibandingkan dengan metode lecturing atau TCCL (Teacher Centered Content Learning). Artinya, potensi mahasiswa harus benar-benar dilatih dan dipancing keaktifannya melalui berbagai bentuk pengajaran yang mendorong mahasiswa berperan aktif dan proaktif hingga potensinya berubah menjadi kompetensi.

Student Centered Learning (SCL) ditawarkan sebagai alternatif dikarenakan metode TCCL dirasa tidak efektif dalam pengajaran. Unsur-unsur pembentuk partisipasi aktif dalam belajar seperti (i) dorongan untuk memperoleh harapan (effort), (ii) kemampuan mengikuti proses pembelajaran, dan (iii) peluang untuk mengungkapkan materi pembelajaran yang diperolehnya di dunia nyata/masyarakat tidak benar-benar terwujud atau sangat terbatas.

Ciri khas yang dibawa SCL adalah bahwa pusat pembelajaran berada di mahasiswa, artinya lingkungan pendidikan membentuk sistem sedemikian rupa agar mahasiswa mau berperan aktif dalam mendalami ilmu pengetahuan seiring dengan kesadarannya yang semakin meningkat akan kebutuhan terhadap ilmu pengetahuan tersebut. Dengan menyediakan daya dukung yang mencukupi seperti internet, video 
interaktif, tutorial digital, dan lain sebagainya dan sistem yang tepat diharapkan dapat meningkatkan pencapaian pemahaman yang diraih mahasiswa.
Secara lebih rinci, perbedaan SCL dibandingkan TCCL diringkas dalam Tabel 1 di bawah.

Tabel 1. Perbedaan TCCL dan SCL

\begin{tabular}{|c|c|c|c|}
\hline & $\begin{array}{l}\text { Teacher Centered Content } \\
\text { Learning }\end{array}$ & Student Centered Learning & Keyword \\
\hline $\mathbf{a}$ & $\begin{array}{l}\text { Dosen mentransfer } \\
\text { pengetahuan ke mahasiswa }\end{array}$ & $\begin{array}{l}\text { Mahasiswa secara aktif } \\
\text { mengembangkan pengetahuan dan } \\
\text { keterampilan yang dipelajarinya }\end{array}$ & Aktif belajar mandiri \\
\hline b & $\begin{array}{l}\text { Mahasiswa menerima } \\
\text { pengetahuan secara pasif }\end{array}$ & $\begin{array}{l}\text { Mahasiswa secara aktif terlibat di } \\
\text { dalam mengelola pengetahuan }\end{array}$ & Aktif belajar mandiri \\
\hline c & $\begin{array}{l}\text { Lebih menekankan pada } \\
\text { penguasaan materi }\end{array}$ & $\begin{array}{l}\text { Tidak hanya menekankan pada } \\
\text { penguasaan materi tetapi juga dalam } \\
\text { mengembangkan karakter mahasiswa } \\
\text { (life-long learning) }\end{array}$ & Pengembangan Karakter \\
\hline d & $\begin{array}{l}\text { Biasanya memanfaatkan } \\
\text { media tunggal }\end{array}$ & $\begin{array}{l}\text { Memanfaatkan banyak media } \\
\text { (multimedia) }\end{array}$ & Multimedia \\
\hline e & $\begin{array}{l}\text { Fungsi dosen atau pengajar } \\
\text { sebagai } \\
\text { pemberi informasi utama dan } \\
\text { evaluator }\end{array}$ & $\begin{array}{l}\text { Fungsi dosen sebagai fasilitator dan } \\
\text { evaluasi dilakukan bersama dengan } \\
\text { mahasiswa. }\end{array}$ & $\begin{array}{l}\text { Dosen dan mahasiswa } \\
\text { belajar bersama }\end{array}$ \\
\hline $\mathbf{f}$ & $\begin{array}{l}\text { Proses pembelajaran dan } \\
\text { penilaian } \\
\text { dilakukan secara terpisah }\end{array}$ & $\begin{array}{l}\text { Proses pembelajaran dan penilaian } \\
\text { dilakukan saling berkesinambungan } \\
\text { dan terintegrasi }\end{array}$ & $\begin{array}{l}\text { Berkesinambungan dan } \\
\text { integrasi }\end{array}$ \\
\hline g & $\begin{array}{l}\text { Menekankan pada jawaban } \\
\text { yang benar } \\
\text { Saja }\end{array}$ & $\begin{array}{l}\text { Penekanan pada proses } \\
\text { pengembangan pengetahuan. } \\
\text { Kesalahan dinilai dapat menjadi } \\
\text { salah satu sumber belajar. }\end{array}$ & $\begin{array}{l}\text { Dosen dan mahasiswa } \\
\text { belajar bersama }\end{array}$ \\
\hline h & $\begin{array}{l}\text { Iklim belajar lebih } \\
\text { individualis dan } \\
\text { Kompetitif }\end{array}$ & $\begin{array}{l}\text { Iklim yang dikembangkan lebih } \\
\text { bersifat kolaboratif, suportif dan } \\
\text { kooperatif }\end{array}$ & $\begin{array}{l}\text { Kolaboratif, suportif dan } \\
\text { kooperatif }\end{array}$ \\
\hline $\mathbf{i}$ & $\begin{array}{l}\text { Hanya mahasiswa yang } \\
\text { dianggap } \\
\text { melakukan proses } \\
\text { pembelajaran }\end{array}$ & $\begin{array}{l}\text { Mahasiswa dan dosen belajar } \\
\text { bersama di dalam mengembangkan } \\
\text { pengetahuan, konsep dan } \\
\text { keterampilan. }\end{array}$ & $\begin{array}{l}\text { Dosen dan mahasiswa } \\
\text { belajar bersama }\end{array}$ \\
\hline $\mathbf{j}$ & $\begin{array}{l}\text { Perkuliahan merupakan } \\
\text { bagian } \\
\text { terbesar dalam proses } \\
\text { pembelajaran }\end{array}$ & $\begin{array}{l}\text { Mahasiswa dapat belajar tidak hanya } \\
\text { dari perkuliahan saja tetapi dapat } \\
\text { menggunakan berbagai cara dan } \\
\text { kegiatan }\end{array}$ & Multimedia \\
\hline $\mathbf{k}$ & $\begin{array}{l}\text { Penekanan pada tuntasnya } \\
\text { materi } \\
\text { Pembelajaran }\end{array}$ & $\begin{array}{l}\text { Penekanan pada pencapaian } \\
\text { kompetensi peserta didik dan bukan } \\
\text { tuntasnya materi. }\end{array}$ & Mencapai kompetensi \\
\hline $\mathbf{l}$ & $\begin{array}{l}\text { Penekanan pada bagaimana } \\
\text { cara dosen } \\
\text { melakukan pembelajaran }\end{array}$ & $\begin{array}{l}\text { Penekanan pada bagaimana cara } \\
\text { mahasiswa dapat belajar dengan } \\
\text { menggunakan berbagai bahan } \\
\text { pelajaran, metode interdisipliner, } \\
\text { penekanan pada problem based } \\
\text { learning dan skill competency. }\end{array}$ & $\begin{array}{l}\text { Multimedia, } \\
\text { Interdisipliner, mencapai } \\
\text { kompetensi }\end{array}$ \\
\hline
\end{tabular}


Menurut UU Sisdiknas No.2 tahun 2003 disebutkan bahwa yang dimaksud dengan pembelajaran adalah interaksi antara pendidik, peserta didik, dan sumber belajar di dalam lingkungan belajar tertentu. Jika kita asosiasikan pengertian tersebut dengan ciriciri metode SCL maka dihasilkan skema seperti gambar di bawah ini:

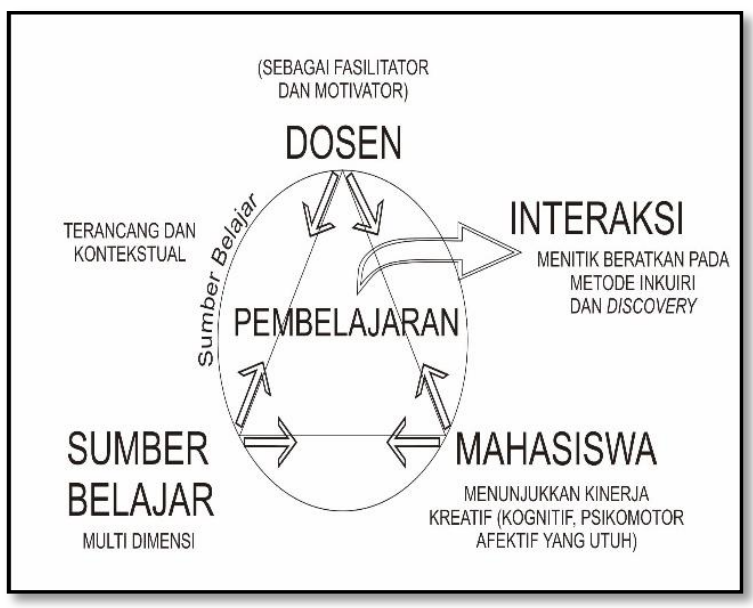

Gambar 1. Hubungan interaksi antara Dosen, Mahasiswa dan Sumber Belajar

Berdasarkan permasalahan yang ada pada kondisi pengajaran mata kuliah Jarkom Politeknik Telkom, maka dirumuskan dan diajukan penyelesaian permasalahan sebagai berikut:

1) Bagaimana mengimplementasikan SCL ke dalam perkuliahan Jaringan Komputer?

2) Perangakat apa saja yang dibutuhkan untuk membangun sistem pendukung SCL pada perkuliahan Jaringan Komputer?

3) Seberapa handal SCL yang diterapkan jika dibandingkan dengan pembelajaran konvensional pada perkuliahan Jaringan Komputer?

\section{Metode-metode pembelajaran SCL}

Terdapat beragam metode pembelajaran untuk SCL, di antaranya adalah: (1) Small Group Discussion; (2) Role-Play \& Simulation; (3) Case Study; (4) Discovery Learning (DL); (5) Self-Directed Learning (SDL); (6) Cooperative Learning (CL); (7) Collaborative Learning (CbL); Selain ketujuh model tersebut, masih banyak model pembelajaran lain yang belum dapat disebutkan satu persatu, bahkan setiap pendidik/dosen dapat pula mengembangkan model pembelajarannya sendiri.

\section{Small Group Learning (SGL)}

Diskusi adalah salah satu elemen belajar secara aktif dan merupakan bagian dari banyak model pembelajaran SCL yang lain, seperti CL, CbL, PBL, dan lain-lain. Mahasiswa peserta kuliah diminta membuat kelompok kecil (5 sampai 10 orang) untuk mendiskusikan bahan yang diberikan oleh dosen atau bahan yang diperoleh sendiri oleh anggota kelompok tersebut. Dengan aktivitas kelompok kecil, mahasiswa akan belajar: (a) Menjadi pendengar yang baik; (b) Bekerjasama untuk tugas bersama; (c) Memberikan dan menerima umpan balik yang konstruktif; (d) Menghormati perbedaan pendapat; (e) Mendukung pendapat dengan bukti; dan (f) Menghargai sudut pandang yang bervariasi (gender, budaya, dan lainlain). Adapun aktivitas diskusi kelompok kecil dapat berupa: (a) Membangkitkan ide; (b) Menyimpulkan poin penting; (c) Mengases tingkat skill dan pengetahuan; (d) Mengkaji kembali topik di kelas sebelumnya; (e) Menelaah latihan, quiz, tugas menulis; (f) Memproses outcome pembelajaran pada akhir kelas; (g) Memberi komentar tentang jalannya kelas; (h) Membandingkan teori, isu, dan interpretasi; (i) Menyelesaikan masalah; dan (j) Brainstroming.

Bentuk pelaksanaan SGL dapat dimodifikasi dengan membagi beberapa peran dalam kelompok diskusi. Peran-peran yang dapat diterapkan adalah Presenter, Moderator dan Penguji. Tugas Presenter adalah menyiapkan presentasi dan bahan diskusi. Tugas Penguji adalah menanyakan hal-hal yang bisa dikembangkan dari materi presentasi. Presenter tidak selalu harus menjawab pertanyaan dari Penguji. Jika ada pertanyaan yang tidak dimengerti, Presenter dapat mengaku belum mengetahui jawaban dari pertanyaan yang ditanyakan dan akan menjawabnya dalam laporan diskusi. Tugas moderator adalah menengahi diskusi dan menghidupkan diskusi. Jika diskusi sudah selesai, presenter berkewajiban membuat laporan diskusi. 


\section{Cooperative Learning (CL)}

CL adalah metode belajar berkelom-pok yang dirancang oleh dosen untuk memecahkan suatu masalah/kasus atau mengerjakan suatu tugas. Kelompok ini terdiri atas beberapa orang mahasiswa, yang memiliki kemampuan akademik yang beragam.

Metode ini sangat terstruktur, karena pembentukan kelompok, materi yang dibahas, langkah-langkah diskusi serta produk akhir yang harus dihasilkan, semuanya ditentukan dan dikontrol oleh dosen. Mahasiswa dalam hal ini hanya mengikuti prosedur diskusi yang dirancang oleh dosen. Pada dasarnya CL seperti ini merupakan perpaduan antara teacher-centered dan student-centered learning. CL bermanfaat untuk membantu menumbuhkan dan mengasah: (a) kebiasaan belajar aktif pada diri mahasiswa; (b) rasa tanggungjawab individu dan kelompok mahasiswa; (c) kemampuan dan keterampilan bekerjasama antar mahasiswa; dan (d) keterampilan sosial mahasiswa.

\section{Collaborative Learning (CbL)}

$\mathrm{CbL}$ adalah metode belajar yang menitikberatkan pada kerjasama antar mahasiswa yang didasarkan pada konsensus yang dibangun sendiri oleh anggota kelompok. Masalah/tugas/kasus memang berasal dari dosen dan bersifat open ended, tetapi pembentukan kelompok yang didasarkan pada minat, prosedur kerja kelompok, penentuan waktu dan tempat diskusi/kerja kelompok, sampai dengan bagaimana hasil diskusi/kerja kelompok ingin dinilai oleh dosen, semuanya ditentukan melalui konsensus bersama antar anggota kelompok.

\section{E-Quiz}

E-quiz adalah bagian dari e-learning yang berupa metode quis yang dilakukan secara online melaui antarmuka web. Melalui E-quiz dosen dapat membuat quiz secara online, memperoleh hasil quiz secara real time, dan juga paperless. Beberapa fitur Equiz yang sangat membantu kerja dosen adalah: Soal digenerate secara random, mendukung Multiple Choice One Answer, Multiple Choice Multi Answer, soal benar/salah, soal Isian, soal menjodohkan, dan soal Essay. Dosen dapat memperoleh laporan ujian secara detail, dosen dapat mengatur batas waktu mengerjakan ujian dan mengagendakan waktu pelaksanaan ujian. Ujian dapat dilaksanakan di rumah (Sebagai sarana latihan soal) atau di kelas (untuk assessment). Beberapa aplikasi E-quiz yang populer adalah E-quizzer.com, quizstar.com, proprofs.com, quibblo.com dll. Yang perlu dosen siapkan adalah bank soal yang cukup banyak beserta kunci jawabannya.

\section{Cloud Based Sharing Files}

Seiring dengan populernya teknologi Cloud, bermunuculan pula aplikasi-aplikasi inovatif yang belum pernah ada sebelum dikembangkannya teknologi Cloud. Salah satu penerapannya adalah untuk penggunaan berbagi file atau yang disebut Cloud Based Sharing Files $(C B S F)$. Perbedaannya dengan berbagi file versi client-server (FTP server) adalah, dengan diletakkannya file di cloud, maka file dapat diedit dan diupdate secara realtime kepada klien-klien yang sama-sama berbagi folder yang serupa. Disini muncul peluang untuk bekerja kolaboratif dan kooperatif. Mahasiswa dapat mengerjakan tugas bersama tanpa harus berada di tempat yang sama (remote). Dengan begitu pembelajaran tidak harus di satu tempat, melainkan placeless di dunia maya. Dengan adanya fitur notifikasi, maka CBSF sangat mendukung kerja kolaboratif, mendukung fitur chat lewat file .txt, dan berbagi file-file yang dibutuhkan dalam perkuliahan.

Tidak hanya itu, assessment juga dapat dilakukan secara online dengan cara meletakkan soal yang dienkripsi (boleh tipe .ZIP atau .RAR yang diamankan dengan password) ke CBSF. Password baru akan diberitahu ketika mahasiswa sudah berada di kelas, dengan begitu assessment bisa dilakukan secara digital dan paperless. Aplikasi yang cukup populer adalah Dropbox, Windows Live Mesh, SpiderOak, SugarSync, dan Wuala.

\section{Kompetisi dan Rewarding}

Dalam kamus merriam webster, kompetisi berarti "the effort of two or more parties acting independently to secure the business of a third party by offering the most 
favorable terms" (Sebuah usaha dari 2 pihak atau lebih yang melakukan sesuatu secara independen untuk mendapat sesuatu dari pihak ketiga dengan menyediakan aksi yang diinginkan). Dalam kamus besar bahasa Indonesia: penghargaan artinya perbuatan menghargai; penghormatan. Penghargaan merupakan sesuatu hal yang memang diharapkan oleh sebagian manusia sebagai makhluk sosial. Sebuah penghargaan akan didapat oleh seseorang dikarenakan jasa-jasa atau sesuatu hal yang dilakukan atau diberikan. Akibat dari perbuatan yang dilakukan seseorang tersebut ia mendapat pujian atau benda tertentu secara khusus sebagai bentuk penghargaan. Biasanya penghargaan merupakan sesuatu yang dibanggakan oleh banyak orang, karena pemberiannya diberikan kepada orang-orang tertentu secara khusus.

Dengan memberlakukan suasana kompetisi dalam kelas, secara tidak langsung dosen mendorong masing-masing mahasiswa untuk bekerja sekeras mungkin untuk lebih baik dibanding mahasiswa lain. Langkah ini dinilai lebih efektif dibanding sekedar menyuruh mahasiswa untuk belajar. Agar efektif, kompetisi harus dilengkapi antara penghargaan (reward), hukuman (punishment), atau keduanya.

Sukarni (2010) menyebutkan ada beberapa tujuan dalam pemberian penghargaan ini, diantaranya adalah:

1) Meningkatkan perhatian peserta didik.

2) Memudahkan peserta didik selama proses pembelajaran.

3) Membangkitkan dan memelihara motivasi.

4) Mengendalikan dan mengubah tingkah laku belajar yang negatif ke arah tingkah laku belajar yang produktif.

5) Mengatur dan mengembangkan diri sendiri dalam mengajar.

6) Mengarahkan cara berpikir tingkat tinggi.

$$
\text { Cara dalam memberikan }
$$

penghargaan/penguatan bermacam-macam diantaranya adalah:

1) Cara verbal, contohnya adalah "bagus", "benar', "tepat", "pekerjaan anda baik sekali", "saya gembira dengan hasil pekerjaan anda", dan sebagainya.
2) Dengan mimik dan gerakan badan: senyuman, anggukan, acungan jempol, tepuk tangan. Hal ini dapat diikuti dengan cara verbal.

3) Penguatan dengan cara mendekati: berdiri di samping peserta didik, berjalan menuju kearah peserta didik, duduk dekat peserta didik/kelompok dan sebagainya. Hal ini dapat dibarengi dengan penguatan verbal.

4) Dengan sentuhan: Dosen dapat menyatakan persetujuan dan penghargaan terhadap mahasiswa atas usaha dan penampilannya dengan cara menepuk pundak, menjabat tangan atau mengangkat tangan peserta didik yang berprestasi di kelas. Penggunaan penguatan ini harus bijaksana artinya dipertimbangakan umur, jenis kelamin dan latar kebudayaan setempat (umpamanya mengelus-elus rambut).

5) Dengan kegiatan yang menyenangkan: kegiatan atau tugas yang menyenangkan dapat dipakai sebagai penguatan. Misal: mahasiswa yang dapat menyelesaikan tugasnya terlebih dahulu dan baik dapat diberi tugas untuk membantu temannya yang kesulitan dan sebagainya.

6) Dengan simbol ataupun benda: komentar tertulis pada buku peserta didik, kartu bergambar, bintang, lencana dan lainnya asal tidak terlalu mahal tapi bermakna simbolis.

\section{Token Game}

Token Game adalah mekanisme penilaian mahasiswa berbasis keaktifan dalam bertanya. Dalam token game, setiap mahasiswa dijanjikan reward berupa kesempatan remedial assesmen mahir untuk setiap kajian jika mampu bertanya sejumlah 30 kali selama perkuliahan berlangsung. Setiap mahasiswa dibekali form "TIKET REMEDIAL" yang berisi 30 kotak kosong. Setiap mahasiswa bertanya (dengan caramengacungkan tangan) maka dosen akan membubuhkan tanda tangan (atau cap) sebagai tanda pencapaian. Di akhir semester dosen hanya akan memberikan kesempatan remedial hanya pada mahasiswa yang sudah mengumpulkan 30 tanda tangan dosen.

Tidak hanya itu, dosen dapat menambah aturan dengan memberi penghargaan jika sudah mengumpulkan 10 tanda tangan atau 
20 tanda tangan (kondisional). Bentuk rewardnya bisa berupa informasi no. Handphone dosen, facebook approval, Chat approval, konsultasi ke rumah dosen dan lain sebagainya. Bentuk reward ini dapat disesuaikan dengan karakter tiap dosennya. Mekanisme ini menumbuhkan nuansa kompetisi di kelas, keaktifan berrtanya dan inkuiri aktif mahasiswa. Selain itu, mekanisme ini mendorong komunikasi dua arah selama pembelajaran di dalam atau di luar kelas. Dokumentasi dari Token Game ini dapat diolah untuk mengevaluasi proses pengajaran di kelas. Metode ini juga menumbuhkan keseriusan dalam mahasiswa untuk mempelajari mata kuliah, karena satu-satunya syarat mereka mendapat remedial adalah aktif bertanya sampai dapat 30 token.

\section{Pembagian Tingkat Kompetensi}

(Kompetensi Dasar, Menengah dan Mahir)

Dalam perspektif Kurikulum Berbasis Kompetensi (KBK), Kompetensi dapat dibagi menjadi 3 bagian, yaitu Kompetensi Dasar, Kompetensi Menengah, dan Kompetensi Mahir. Pembagian tersebut didasarkan atas tingkat kesuilitan kompetensi yang harus dikuasai oleh mahasiswa dalam menyelesaikan sebuah mata kuliah. Dalam mata kuliah jaringan komputer, kompetensi dasar mencakup kemampuan untuk mengetahui teori dasar jaringan komputer, kompetensi menengah mencakup kemampuan praktis jaringan komputer tingkat dasar berkaitan dengan kajian/topik tertentu, sementara kompetensi mahir mencakup kemampuan praktis TCCL. jaringan komputer tingkat lanjut dari kompetensi menengah. Masing-masing kompetensi sudah didefinikasikan bahan kajian yang harus dipelajari, modul praktikum yang harus dicoba dan tujuan instruksional kajiannya. Bentuk pengujian berbentuk berjenjang. Jika mahasiswa lulus ujian kompetensi dasar, maka mahasiswa berhak mengajukan assessment menengah. Jika mahasiswa lulus kompetensi menengah, maka mereka boleh mengajukan diri untuk melaksanakan asessment mahir.

\section{METODOLOGI PENELITIAN Implementasi SCL pada kuliah Jaringan Komputer Sistem Pengajaran}

Dari Tabel 1 kita sudah mengelompokkan ciri-ciri SCL ke dalam beberapa kata kunci, yaitu:

a. aktif belajar mandiri (ABM);

b. pengembangan karakter $(\mathrm{PK})$;

c. multimedia (M);

d. dosen dan mahasiswa belajar bersama (DMBB);

e. berkesinambungan dan integrasi (BI);

f. kolaboratif, suportif, dan kooperatif (KSK);

g. mencapai kompetensi (MK).

Dari kelompok kata kunci ini kita padankan dengan alat pendidikan yang sekiranya dapat memenuhi kebutuhan tersebut. $\mathrm{Pa}-$ da akhirnya setelah alat pendidik-an ini diterapkan, kita akan mengukur efektifitasnya dan membanding-kannya dengan pola pembelajaran

Tabel 2. Penerapan SCL

\begin{tabular}{|l|c|c|c|c|c|c|c|}
\hline & ABM & PK & M & DMBB & BI & KSK & MK \\
\hline Dropbox & & & $\checkmark$ & $\checkmark$ & & $\checkmark$ & \\
\hline $\begin{array}{l}\text { Equizzer } \\
\text { Token Game }\end{array}$ & $\checkmark$ & $\checkmark$ & $\checkmark$ & $\checkmark$ & & $\checkmark$ & \\
\hline Pembagian Tingkat Kompetensi & & $\checkmark$ & & & & $\checkmark$ & \\
\hline $\begin{array}{l}\text { Small Group Discussion } \\
\text { Lecturing }\end{array}$ & $\checkmark$ & $\checkmark$ & & & & $\checkmark$ & \\
\hline Praktikum & $\checkmark$ & $\checkmark$ & $\checkmark$ & & & & $\checkmark$ \\
\hline Cooperative Learning & $\checkmark$ & $\checkmark$ & & & & $\checkmark$ & \\
\hline Collaborative Learning & $\checkmark$ & $\checkmark$ & & & & $\checkmark$ & \\
\hline
\end{tabular}

Proses implementasi dilakukan dengan pertama-tama membagi kelas 40 mahasiswa menjadi lima kelompok diskusi kecil (berjumlah 6-7 orang per kelompok). 
Selain pembentukan kelompok diskusi, dipilih juga lima orang penanya yang akan bertanya ke setiap kelompok. Satu orang penanya untuk satu kelompok. Penanya bertugas untuk menanyakan minimal sepuluh pertanyaan ke setiap diskusi kelompok. Kelompok diskusi bertugas membuat slide presentasi, melakukan diskusi dan presentasi ke penanya, kemudian membuat laporan diskusi. Satu orang dari kelompok presenter harus ada yang berinisiatif menjadi moderator.

Di pertemuan perdana Dosen mengumumkan aturan main Token Game dan Assessment. Aturan Token game yang diimplementasikan adalah maksimal nilai token per pertemuan adalah dua token per seorang yang bertanya. Aturan ini dimaksudkan agar kompetisi tetap adil dengan memberikan setiap mahasiswa hak untuk bertanya tanpa didominasi oleh mahasiswa tertentu (dengan cara terus bertanya dan tidak memberikan kesempatan bertanya kepada mahasiswa lainnya). Dalam SGLyang berperan sebagai penanya dihargai dengan dua token. Peserta diskusi yang aktif dari kelompok presenter mendapat dua atau satu token tergantung seberapa aktif dia melakukan diskusi. Moderator mendapat satu token.

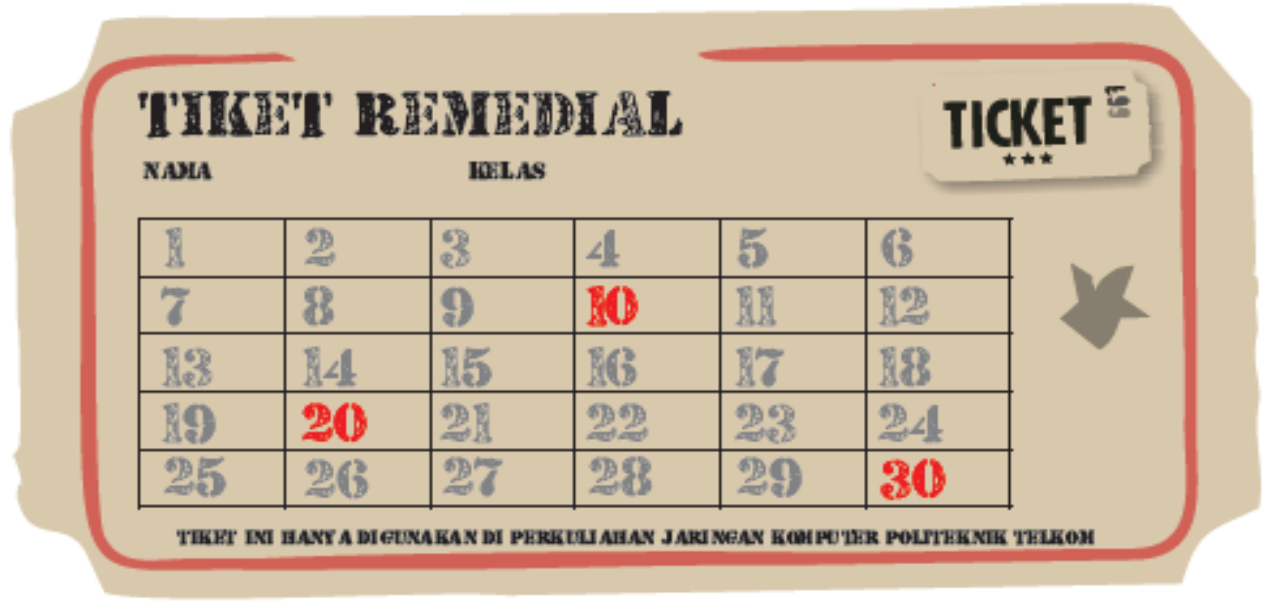

Gambar 2.Template TIKET REMEDIAL

\section{Assessment}

Untuk Assessment, dosen mensyaratkan bahwa yang berhak mengikuti assessment kompetensi mahir adalah hanya bagi mahasiswa yang sudah lulus assessment kompetensi menengah. Mahasiswa yang berhak mengikuti assessment menengah adalah mahasiswa yang sudah lulus assessment dasar.

Materi Jaringan Komputer dikelompokkan menjadi materi teori dan praktek. Dari $10 \mathrm{Bab}$, dibuat dan dikelompokkan menjadi 5 kajian (teori dan praktek) dan masing-masing kajian dibuat paket assessment dasar untuk mengukur kompetensi dasar, assesment menengah untuk mengukur kompetensi menengah, dan assessment mahir untuk mengukur kompetensi mahir.
Kompetensi dasar diukur melalui quis online menggunakan Equizzer.com. Equiz zer.com dipilih karena fiturnya yang lengkap, gratis dan kemudahan yang diberikan dalam mengolah soal, mengatur quiz, melihat pencapaian dan tampilan yang cukup baik. Selain itu, Equizzer juga mendukung random soal dan random jawaban multiple choice. Hal ini yang tidak didukung oleh layanan lain yang serupa, padahal random soal dan random choice sangat dibutuhkan untuk menciptakan sistem quiz yang tidak ada kunci jawaban tunggal (mahasiswa tidak bisa membuat kunci jawaban untuk dibocorkan ke mahasiswa lainnya). Perbandingan antara Equizzer.com dengan online quiz lainnya diperlihatkan dalam Tabel 3. 
Tabel 3. Perbandingan berbagai situs quis online

\begin{tabular}{|c|c|c|c|c|c|}
\hline No. & $\begin{array}{l}\text { Fitur yang } \\
\text { dinilai }\end{array}$ & $\begin{array}{l}\text { E-quizzer } \\
\text {.com }\end{array}$ & $\begin{array}{l}\text { Quizstar } \\
\text {.com }\end{array}$ & $\begin{array}{l}\text { Proprofs } \\
\text {.com }\end{array}$ & $\begin{array}{l}\text { Quibblo } \\
\text {.com }\end{array}$ \\
\hline 1 & Tampilan & $\begin{array}{l}\text { Cukup baik, padat } \\
\text { dan ada tampilan } \\
\text { iklannya }\end{array}$ & $\begin{array}{l}\text { Cukup baik, padat } \\
\text { dan ada tampilan } \\
\text { iklannya }\end{array}$ & $\begin{array}{l}\text { Intuitif dan } \\
\text { menarik }\end{array}$ & Menarik \\
\hline 2 & Keanggotaan & Gratis & Gratis & $\begin{array}{l}\text { Berbayar jika } \\
\text { ingin mendapat } \\
\text { seluruh fitur }\end{array}$ & Gratis \\
\hline 3 & $\begin{array}{l}\text { Kemudahan } \\
\text { membuat soal }\end{array}$ & $\begin{array}{l}\text { Mendukung fitur } \\
\text { File } \\
\text { (Comma } \\
\text { Separated Value), } \\
\text { membuat soal di } \\
\text { websitenya, }\end{array}$ & $\begin{array}{l}\text { Tidak ada fitur } \\
\text { CSV, yang ada } \\
\text { adalah membuat } \\
\text { soal di websitenya } \\
\text { langsung }\end{array}$ & $\begin{array}{l}\text { Membuat soal di } \\
\text { websitenya }\end{array}$ & $\begin{array}{l}\text { Membuat } \\
\text { soal di } \\
\text { websitenya }\end{array}$ \\
\hline 4 & $\begin{array}{l}\text { Kemudahan } \\
\text { melihat hasil } \\
\text { assessment }\end{array}$ & $\begin{array}{lr}\text { Laporan } & \text { quis } \\
\text { diformat per kelas } \\
\text { per kuis per anak } \\
\text { dalam } r \text { bentuk } \\
\text { teks. }\end{array}$ & $\begin{array}{lr}\text { Laporan } & \text { quis } \\
\text { dibuat } & \text { dengan } \\
\text { dukungan } & \text { grafik } \\
\text { dan teks } & \end{array}$ & $\begin{array}{l}\text { Laporan quis } \\
\text { dibuat dibuat } \\
\text { dengan dukungan } \\
\text { grafik dan teks }\end{array}$ & $\begin{array}{l}\text { Tidak ada } \\
\text { laporan quis }\end{array}$ \\
\hline 5 & $\begin{array}{l}\text { Model soal } \\
\text { yang didukung }\end{array}$ & $\begin{array}{l}\text { Multiple choice } \\
\text { one } \\
\text { Multiple choice } \\
\text { multiple answer, } \\
\text { essay, pertanyaan } \\
\text { benar-salah, fill in } \\
\text { the blank question }\end{array}$ & $\begin{array}{l}\begin{array}{l}\text { Multiple choice } \\
\text { one } \\
\text { Multiple choice }\end{array} \\
\text { multiple answer, } \\
\text { essay, pertanyaan } \\
\text { benar-salah, fill in } \\
\text { the blank question }\end{array}$ & $\begin{array}{l}\begin{array}{l}\text { Multiple choice } \\
\text { one } \\
\text { Multiple choice }\end{array} \\
\text { multiple answer, } \\
\text { essay, pertanyaan } \\
\text { benar-salah, fill in } \\
\text { the blank question }\end{array}$ & $\begin{array}{l}\text { Multiple } \\
\text { choice one } \\
\text { answer. }\end{array}$ \\
\hline 6 & $\begin{array}{l}\text { Manajemen } \\
\text { user dan dosen }\end{array}$ & 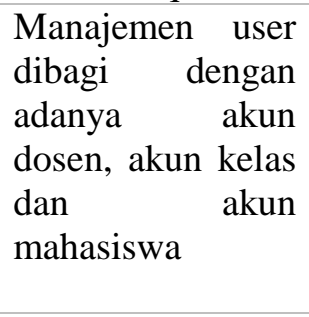 & 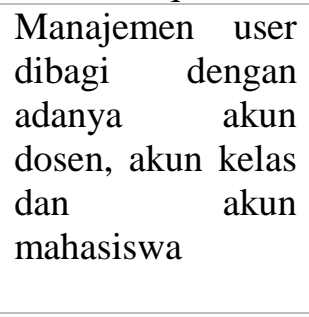 & 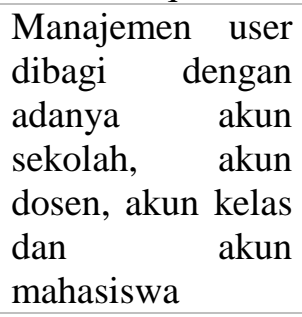 & $\begin{array}{l}\text { Tidak ada } \\
\text { manajemen } \\
\text { user }\end{array}$ \\
\hline 7 & $\begin{array}{l}\text { Fitur }- \text { fitur } \\
\text { pendukung }\end{array}$ & $\begin{array}{l}\text { Random soal, } \\
\text { random jawaban, } \\
\text { feedback, }\end{array}$ & $\begin{array}{l}\text { Random jawaban, } \\
\text { feedback, }\end{array}$ & $\begin{array}{l}\text { Penghargaan } \\
\text { berupa sertifikat } \\
\text { dengan desain } \\
\text { yang menarik }\end{array}$ & $\begin{array}{l}\text { Paling sedikit } \\
\text { diantara } \\
\text { lainnya }\end{array}$ \\
\hline 8 & $\begin{array}{l}\text { Unlimited } \\
\text { assessment? }\end{array}$ & ya & ya & $\begin{array}{l}\text { Untuk versi gratis } \\
\text { hanya diberi jatah } \\
100 \text { kredit (100 } \\
\text { kali assessment) }\end{array}$ & ya \\
\hline
\end{tabular}

\section{berikut:}

Settingan equizzer dibuat sebagai

1) Tiap kajian dipersiapkan 150 bank soal multiple choice one answer.

2) Tiap quis menggenerate 10 soal random dari bank soal. Pilihan jawaban juga dibuat random.

3) Jika mahasiswa gagal mencapai nilai sempurna, maka mahasiswa harus mengambil kembali quis online dengan resiko soal yang digenerate sudah berbeda, dengan pilihan jawaban yang berbeda pula.

4) 10 soal ditampilkan sekaligus. Nilai tidak akan keluar sebelum seluruh soal ditentukan jawabannya oleh mahasiswa.

5) Tiap quis diberi batasan waktu untuk dikerjakan antara 10 sampai 20 menit. Untuk soal teori 10 menit. Untuk soal hitungan seperti subnetting 20 menit.

6) Jika mahasiswa berhasil menjawab 10 soal dengan sempurna, maka akan muncul 
secret words. Secret words ini nantinya harus diemailkan oleh mahasiswa ke email dosen. Dengan begitu dosen bisa merekam siapa saja mahasiswa yang sudah lulus assessment dasar. Meskipun begitu, $e$ quizzer sendiri sudah menyediakan rekaman lengkap hasil assessment mahasiswa jika dosen mau melihatnya.

7) Dosen dapat menentukan kapan sebuah quis itu available untuk dikerjakan mahasiswa.

8) Assesment boleh dilakukan di rumah sebagai latihan. Namun, yang dianggap sebagai assessment resmi adalah yang dikerjakan di kelas. Ada peluang memang soal yang sudah dilatih di rumah akan keluar kembali di assessment resmi. Meskipun begitu ada trade off untuk penentuan nilai yang akan dibahas di subbab selanjutnya.

Kompetensi menengah diukur melalui ujian praktikum terbimbing. Dosen sudah menyiapkan modul praktikum yang lengkap baik dari teori pendukung, langkah kerja dan soal-soal yang perlu dijawab. Di sini mahasiswa dibimbing oleh asisten praktikum dan diberi kesempatan untuk mencoba modul praktikum sampai berhasil. Jika masih gagal, mahasiswa diminta untuk mencoba lagi sampai berhasil. Mahasiswa diminta proaktif bertanya ke asisten praktikum jika ada yang tidak dimengerti. Mahasiswa dikatakan lulus assessment menengah jika memenuhi dua kondisi: a) lulus assessment dasar b) berhasil mencapai tujuan praktikum sesuai modul yang telah diberikan.

Kompetensi mahir diukur melalui berbagai metode yaitu: a) Oral test b) Tes tertulis c) Tes praktek, d) menjelaskan video bisu, e) menjelaskan skema bergerak.

Oral test yang digunakan adalah oral test satu arah yang berbatas waktu. Dalam ujian mahasiswa diminta menyampaikan berbagai hal yang dia ketahui mengenai topik pembelajaran yang ditentukan selama batas waktu tertentu. Biasanya antara 3 sampai 4 menit. Tantangannya adalah mahasiswa tidak diberi kesempatan untuk mengambil jeda (diam tidak berbicara). Metode ini digunakan untuk menguji hafalan mahasiswa mengenai teori yang dipelajari. Jika mahasiswa diam terlalu lama, dosen berhak membatalkan ujian, dan mahasiswa tersebut dinyatakan tidak lulus.

Tes tertulis diadakan untuk soal-soal hitungan jaringan komputer yaitu subnetting CIDR dan VLSM. Mahasiswa disediakan 2 soal hitungan dan diminta mengerjakan dengan berbatas waktu tertentu.

berikut:

Aturan tes praktik adalah seperti

1) Dosen menantang mahasiswa untuk mengimplementasikan tugas tertentu.

2) Dosen membebaskan metode yang digunakan untuk mengerjakan tugas tersebut selama tujuan praktik tercapai.

3) Jika tujuan praktik tercapai, maka mahasiswa tersebut dinyatakan lulus assesment mahir

Yang dimaksud menjelaskan video bisu adalah Dosen sudah mempersiapkan sebuah video peraga yang menjelaskan sebuah proses yang terjadi dalam jaringan komputer. Video itu sengaja tidak diisi dengan suara narasi untuk keperluan assessment mahir. Mahasiswa diminta menjadi narator untuk video tersebut. Mahasiswa dinyatakan lulus jika mampu dengan lancar menjelaskan video bisu.

Yang dimaksud menjelaskan skema bergerak adalah dosen sudah menyediakan beberapa skema bergerak dalam format .swf mengenai proses-proses yang terjadi di jaringan seperti perutingan, algoritma link state dan distance vector, prorokol - protokol jaringan, cara kerja internet dan lainnya. Mahasiswa diminta menjelaskan beberapa skema saja yang dipilih secara random. Jika mahasiswa berhasil menjelakan skema yang dimaksud maka mahasiswa dinyatakan lulus. Skema bergerak yang digunakan adalah buatan visualland.com.

Saat pembelajaran dosen membagi sesi kelas menjadi 2 subsesi. Subsesi pertama adalah diskusi mahasiswa, sesi kedua adalah lecturing dosen. Di pertemuan lain format bisa dirubah menjadi sesi pertama diskusi, sesi kedua adalah praktikum. Bisa juga seluruh sesi digunakan untuk assessement. Cooperative learning dan Collaborative learning dilakukan di luar kelas dengan menggunakan tools equizzer dan dropbox. 
CBSF yang digunakan adalah Dropbox.com. Fitur dropbox yang beragam membantu terjadinya proses kerja kolaboratif pada pembelajaran mata kuliah jarkom. Ketika mahasiswa dalam SGL sudah ditugaskan membuat laporan diskusi, mahasiswa mengunggah berkas laporan ke dropbox. Karena sudah mendukung collaborative activity, file laporan diskusi yang sudah diletakkan di dropbox otomatis terunduh oleh klien dropbox yang dimiliki oleh masing-masing anggota kelompok diskusi. Mekanisme kerja dropbox adalah ketika ada suatu file yang dimodifikasi oleh seseorang, maka otomatis perubahan tersebut juga diupdate untuk file yang disimpan oleh klien dropbox lainnya, selama pengguna dropbox dalam keadaan online. Kita juga bisa melakukan chatting menggunakan file berformat .txt yang diletakkan di dropbox. Setiap ada perubahan file di dropbox, akan muncul notifikasi dari windows icon tray yang artinya file kita telah diupdate oleh teman kita di tempat yang lain.

\section{Sistem penilaian}

Sistem penilaian yang digunakan menggunakan index A, A-, B+, B, B-, C, D dan E. Mahasiswa akan mendapat nilai $C$ jika dari 5 kajian mata kuliah Jaringan Komputer keseluruhannya hanya lulus Kompetensi Dasar. Mahasiswa akan mendapat nilai B jika mahasiswa lulus seluruh Kompetensi Dasar dan juga lulus Kompetensi Menengah. Mahasiswa akan mendapat nilai A jika lulus seluruh kompetensi dasar, kompetensi menengah, dan kompetensi mahir. Nilai di antara A dan B (A-, B+), atau antara B dan C (B-) diraih bergantung dari variasi jumlah kelulusan kompetensi dasar, menengah dan mahir.

\section{HASIL DAN PEMBAHASAN}

Secara statistika (sampel diambil dari 2 kelas jaringan komputer pada 3 waktu yang berbeda: Semester Ganjil 2010, Semester Genap 2011 dan Semester Ganjil 2011) ada beberapa aspek yang meningkat seiring penerapan SCL yaitu:
1. Absensi meningkat

Pada pembelajaran Jaringan Komputer sebelum diterapkan SCL, pengajaran bersifat monoton sehingga mahasiswa mudah jenuh dan puncaknya adalah malas kuliah. Pada SCL metode pengajaran menjadi sangat variatif sehingga membuat mahasiswa bersemangat ke kelas menanti metode pengajaran yang baru atau mengejar poin token. Rata-rata kehadiran mahasiswa sebelum SCL adalah 82,7 \%. Setelah penerapan SCL menjadi 95,6\%. Perlu diperhatikan bahwa salah satu syarat kelulusan mata kuliah di Politeknik Telkom adalah tingkat kehadiran lebih dari $80 \%$.

2. Tingkat keaktifan bertanya meningkat Karena perolehan token menentukan mahasiswa boleh remedial atau tidak, maka mahasiswa mau tidak mau harus berani mengacungkan tangan dan bertanya. Bagi beberapa mahasiswa yang masih malu-malu bertanya di tengah pembelajaran ada juga mahasiswa yang sering main ke ruangan dosen untuk bertanya, atau ada juga yang ketika berpapasan dengan dosen memanfaatkan kesempatan tersebut untuk bertanya. Momen ini juga semakin membuat hubungan dosen dan mahasiswa menjadi lebih cair. Keaktifan mahasiswa sebelum diterapkan SCL adalah rata-rata 7/40 mahasiswa aktif yang bertanya di kelas $(16,7 \%)$. Setelah SCL yang bertanya menjadi $85 \%$ mahasiswa yang aktif bertanya di kelas.

3. Nilai rata-rata mahasiswa meningkat Data nilai di semester ganjil 2010 sebelum diterapkannya SCL rata-rata untuk nilai $A$ adalah 13,8\% mahasiswa. Untuk nilai B $57,2 \%$ mahasiswa. Untuk nilai dibawah B $29 \%$ mahasiswa.

Data nilai di semester genap 2011 sebelum diterapkannya SCL rata-rata untuk nilai A adalah 19,4\% mahasiswa. Untuk nilai B 62,6\% mahasiswa. Untuk nilai dibawah B $18 \%$ mahasiswa.

Setelah diterapkan SCL, untuk mahasiswa yang berbeda di semester ganjil 2011 
perolehan nilai A dan A- adalah B, dan B- menjadi 24,6\% mahasiswa. Sisanya 53,5\% mahasiswa. Yang mendapat nilai $\mathrm{B}+$, men-dapat nilai $\mathrm{C}, \mathrm{D}$ dan $\mathrm{E}(21,9 \%)$.

Tabel 4.Rekapitulasi nilai mahasiswa peserta mata kuliah Jakrom 2010 - 2011 dari sampel 2 kelas

\begin{tabular}{|l|l|l|l|l|l|l|}
\hline \multirow{2}{*}{ Nilai } & \multicolumn{3}{|c|}{ Semester ganjil 2010 } & \multicolumn{2}{c|}{ Semester genap 2011 } & \multicolumn{2}{c|}{ Semester ganjil 2011 } \\
\cline { 2 - 7 } & jumlah & $\mathbf{\%}$ & jumlah & $\mathbf{\%}$ & jumlah & \% \\
\hline A & 10 & 13,8 & 14 & 19,4 & 32 & 42,6 \\
\hline A- & - & - & - & - & 8 & 10,9 \\
\hline B+ & - & - & - & - & 8 & 10,9 \\
\hline B & 42 & 57,2 & 45 & 62,6 & 6 & 8,2 \\
\hline B- & - & - & - & - & 4 & 5,5 \\
\hline C & 15 & 19,5 & 10 & 13,8 & 10 & 13,6 \\
\hline D & 5 & 6,9 & 2 & 2,8 & 4 & 5,5 \\
\hline E & 2 & 2,6 & 1 & 1,4 & 2 & 2,8 \\
\hline Total & 74 & 100 & 72 & 100 & 74 & 100 \\
\hline
\end{tabular}

Pada semester ganjil 2010 dan semester genap 2011 belum diterapkan nilai A-, B+, B-. Ekivalensi nilai dari sistem TCCL ke SCL adalah $\mathrm{A}=\mathrm{A}$ dan $\mathrm{A}-, \mathrm{B}=\mathrm{B}+, \mathrm{B}$ dan $\mathrm{B}-, \mathrm{C}=\mathrm{C}, \mathrm{D}=\mathrm{D}, \mathrm{E}=\mathrm{E}$.

Dari pengamatan,didapati ada beberapa hal yang membuat pembelajaran Jaringan Komputer lebih efektif dengan menggu-nakan SCL dibanding menggunakan TCCL. Hasil tersebut adalah:

1) Mahasiswa lebih merasa bertanggung jawab terhadap nilai prestasi yang harus ia capai, karena sukses atau tidaknya benarbenar ditentukan oleh seberapa aktif mahasiswa mau berusaha. Hal ini membangun karakter disiplin dan bertanggung jawab pada diri mahasiswa.

2) Lebih banyak pertanyaan muncul karena pengaruh pengerjaan Online Quis equizzer, target pencapaian Assessment Dasar, Menengah dan Mahir, serta diskusi kelompok mandiri di kelas.

3) Interaksi antara dosen dan mahasiswa tidak sebatas di kelas, karena lewat Dropbox Mahasiswa bisa bertukar data dengan dosen dan sesama mahasiswa, menanyakan persoalan yang rumit, berbagi sumber bacaan (ebook) dan melaporkan hasil diskusi kelas.

4) Mahasiswa tidak hanya mengejar nilai, tetapi juga mengejar nilai keaktifan agar mendapat kesempatan remedial di akhir semester. Hal ini membuat mahasiswa yang terbiasa diam pun mau tidak mau harus mulai terbiasa aktif agar memperoleh kesempatan remedial.

5) Nuansa kompetisi diantara mahasiswa membuat pembelajaran Jaringan Komputer lebih relax dan menyenangkan namun tetap serius dalam mencapai nilai sebaikbaiknya.

6) Mahasiswa mengisi waktu di luar perkuliahan untuk menyelesaikan equizzer. Ini membantu mahasiswa untuk terbiasa belajar di luar kelas dengan membuka buku, mencari jawaban di internet dan belajar bersama.

7) Mahasiswa terbiasa untuk berbagi ilmu dan membantu mengembangkan potensi teman-temannya berkaitan dengan materi keterampilan.

8) Perkuliahan Jaringan Komputer semakin irit menggunakan kertas karena untuk assessment dan pembelajaran sudah beralih ke format digital dan dilaksanakan secara online, meskipun tidak optimal karena untuk beberapa hal modul printable masih dibutuhkan.

\section{Need For Improvement}

Di samping terdapat banyaknya kelebihan yang dipetik, ada juga beberapa hal yang perlu diperhatikan dan dicarikan solusinya. Diantaranya sebagai berikut:

a. Karena pengawasannya yang sangat longgar, terkadang ada beberapa mahasiswa yang mengerjakan E-quizzer dengan dibantu mahasiswa lain tanpa melalui proses belajar yang wajar. Tidak wajar disini maksudnya adalah mahasiswa meng- 
gunakan jasa joki untuk membantu menjawabkan soal-soal e-quizzer.

b. Waktu di kelas cukup tersita banyak dengan kegiatan menandatangani Tiket Remedial dan kelulusan kompetensi dasar, menengah dan mahir. Rata-rata untuk mengisi tanda tangan token sekitar 5 sampai 10 menit. Akibatnya efektifitas waktu untuk proses pembelajaran berkurang.

c. Banyak mahasiswa yang bertanya dengan pertanyaan yang kurang berkualitas (tidak penting untuk ditanyakan) demi mendapat token. Sebenarnya isu ini masih menjadi perdebatan apakah merupakan kekurangan atau justru memang bagian dari proses membiasakan mahasiswa jadi aktif bertanya.

d. Fitur paperless masih belum bisa dilaksanakan secara penuh, karena pada saat praktikum ternyata lebih nyaman jika modul masih berupa printable modul, karena laptop digunakan untuk menjalankan program simulasi jaringan.

\section{PENUTUP}

Dari implementasi SCL pada perkuliahan Jaringan Komputer di Politeknik Telkom dapat disimpulkan sebagai berikut:

1. SCL berhasil diimplementasikan pada kelas Jaringan Komputer Politeknik Telkom dengan memperhatikan korelasi antara alat-alat pendidikan dengan definisi pembelajaran berdasarkan UU Sisdiknas no. 2 tahun 2003.

2. Implementasi SCL melibatkan alat-alat pendidikan seperti Equizzer.com, , Small Group Learning(SGL), Collaborative Learning (CL), Cloud Based Sharing Files (CBSF) menggunakan Dropbox.com, Token Game, Lecturing, Praktikum, dan Pembagian assessment menjadi Assessment Dasar, Menengah dan Mahir.

3. Kehandalan SCL dibanding TCCL digambarkan melalui meningkatnya nilai siswa, meningkatnya tingkat keaktifan mahasiswa dan meningkatnya absensi mahasiswa.

Adapun saran agar implementasi SCL dapat lebih baik adalah:

1. Mengeksploit lebih jauh metode-metode lain dari SCL

2. Mengeksploit alat pendidikan lain yang sekiranya dapat lebih efektif dalam mencapai kebutuhan SCL

3. Menambah jumlah bank soal untuk lebih meminimalisir bocornya jawaban dari online quiz

4. Menggunakan infrastruktur lokal untuk pengembangan e-quiz dan e-learning agar lebih handal

5. Menggunakan aplikasi sendiri yang lebih konfigurable dan compact

\section{DAFTAR PUSTAKA}

Kunaefi, T. D.,\& Tim Penyusun. (2008). Buku Panduan Pengembangan Kurikulum Berbasis Kompetensi Pendidikan Tinggi. Jakarta: Direktorat Akademik Direktorat Jenderal Pendidikan Tinggi

Wulandari, N., Umu, L., Dian, Adiprana., \& Novantoni. (2011). Peran Penghargaan Dalam Rangka Meningkatkan Motivasi Belajar Siswa. Bandung: Universitas Pendidikan Bandung

Undang- Undang Republik Indonesia Nomor 20 Tahun 2003 Tentang Sistem Pendidikan (n.d.). diambil dari http://www.dikti.go.id/Archive2007/ UUno20th2003-Sisdiknas.htm

What is equizzer? (n.d.). diambil dari http:// www.equizzer.com/index.php? option $=\mathrm{com}_{\text {_ }}$ content\&task =view $\& \mathrm{id}=1 \&$ Itemid $=1$

Dropbox (n.d.). diambil dari http:// en. wikipedia.org/wiki/Dropbox_\%28se rvice\% 29 